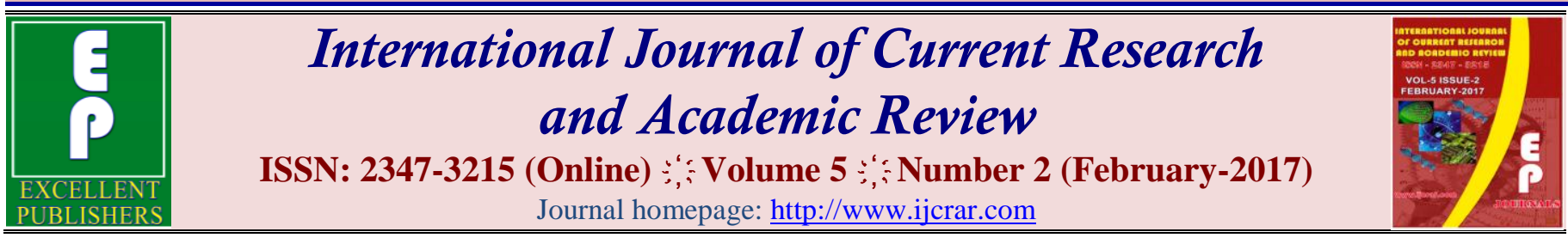

doi: http://dx.doi.org/10.20546/ijcrar.2017.502.006

\title{
Rising Rate of Caesarean Section - A Global Problem
}

\author{
Farzana Rizwan Arain* \\ Taif Medical College, Taif, KSA \\ *Corresponding author
}

\begin{abstract}
To compare the frequency of Caesarean Section (CS), Emergency and Elective CS, indications of Emergency and Elective CS and obstetrician reasons for supporting women choice for caesarian section between a healthcare setting of Saudi Arabia and Pakistan. The retrospective study analyzed the hospital records of all deliveries during the period January, 2012 till December, 2012 at two settings, Muhammad Medical College Hospital (MMCH), Pakistan and Sabatal Alaya Hospital, Saudi Arabia. Data (demographic information, parity and outcome variables i.e., cesarean section or vaginal delivery, elective cesarean section or emergency cesarean section) from the clinical records were retrieved. Importantly, the indicators for cesarean section mentioned in the clinical notes were also recorded. The present study also included the collection primary data on reasons for supporting women choice for caesarian section from obstetricians of Pakistan and Saudi Arabia. The data was analysed using SPSS version 21 and qualitative variables were compared between women delivered at Muhammad Medical College Hospital (MMCH), Pakistan and Sabatal Alaya Hospital, Saudi Arabia using chi square statistics. The retrospective analysis included data of eleven hundred and fifty women who delivered in $\mathrm{MMCH}$ and eight hundred and thirty four deliveries in Sabatal Alaya Hospital, Saudi Arabia. Fifty eight percent of women were delivered through Caesarian section in Pakistan compared to around thirty four percent in Saudi Arabia. The most common indicators for Elective CS among Pakistani and Saudi women were previous CS followed by breech presentation, maternal condition and maternal request. Significant difference lied between indications of Emergency CS between the two countries with most common reasons as difficult labor (26.5\% Vs. 39\%), fetal distress (20.9\% Vs. 17.3\%), Antipartum Hemorrhage (12.7\% Vs. $10.8 \%)$ and breech presentation (10.2\% Vs. 9.7\%). Greater proportion of obstetricians from Saudi Arabia compared to those working in Pakistan accounted women choice $(51.8 \% \mathrm{Vs} 18.2 \%$; p-value < 0.001$)$, previous caesarian section $(87.5 \%$ Vs $68.2 \%$; p-value $=0.035)$, respect for women autonomy $(80.4 \%$ Vs $56.8 \% ; \mathrm{p}$-value $=$ $0.084)$ and legal consequences if something goes wrong $(58.9 \%$ Vs $15.9 \%$; p-value $=$ 0.001 ) as reasons for supporting caesarean delivery. The present study concluded that in both Pakistan and Saudi Arabia CS rate exceeded the acceptable 15\% rate suggested by the World Health Organization (WHO). The obstetricians from Saudi Arabia had more fear of legal consequences, and accounted women choice and respect for women autonomy as reasons for supporting women decision of Elective CS.
\end{abstract}

\section{Article Info}

Accepted: 25 January 2017

Available Online: 20 February 2017

\section{Keywords}

Caesarean section, Elective, Emergency, Maternal request, Indications. 


\section{Introduction}

Caesarean section (CS) is a major surgical procedure and should be performed where clear defined indications are presents that vaginal deliveries are risk for life of mother or baby (Penn et al., 2001). In health settings of developed countries, the World Health Organisation (WHO) has placed an acceptable CS rate of $10 \%$ to $15 \%$ (Appropriate technology for birth, 1985). However, there has been a significant rise in CS in past decade and studies have reported a higher rate and performance of procedure even in situations where not medically recommended or necessary (Dadipoor et al., 2016). The review reported that worldwide, CS rate increased from $6.7 \%$ in 1990 to $19.1 \%$ in 2014 with $14.6 \%$ increase in developing countries and $12.7 \%$ in developed countries. Moreover, in the well developed healthcare settings of United States the cesarean rate increased from $20.7 \%$ in 1996 to $32.8 \%$ in 2011 . This not only poses a burden on scarce health resources and making the healthcare delivery more costly, but also places women life in danger. The study from United Kingdom reported that the risk of maternal deaths from CS is three times more than vaginal delivery (Hall et al., 1999). Moreover, in developed countries increasing number of women are requesting elective CS without any medical or surgical indications as preferred mode of delivery and obstetricians are supporting their choice (Gunnervik et al., 2008).

Considering the rising rate of CS and its impact in terms of increased healthcare cost and higher maternal morbidity and mortality significant number of researches has been done to identify the CS rates. But very few studies have reported the separate indications of Elective and Emergency CS and compared health settings of developed and developing country as being single centre. Moreover, in recent years increasing number of women are requesting CS, the reasons for supporting women choice for caesarian section among obstetricians has not been well investigated. Considering the above mentioned reasons, the study was conducted to compare the prevalence of CS, Emergency and Elective CS, indications of Emergency and Elective CS and obstetrician reasons for supporting women choice for caesarian section between a healthcare setting of developed country Saudi Arabia and a developing country Pakistan.

\section{Materials and Methods}

The retrospective study analyzed the hospital records of all deliveries at two settings, Muhammad Medical
College Hospital (MMCH), Pakistan and Sabatal Alaya Hospital, Saudi Arabia. Muhammad Medical College Hospital was established in 1999, and located at Mirpurkhas, Sindh, Pakistan. While, the second study setting Sabatal Alaya Hospital is located in the Bisha region, part of south western Saudi Arabian province Asir. Both MMCH and Sabatal Alaya Hospital has well established Gynecological department and women from both urban and nearby rural areas visits for ante natal checkups, deliveries and gynecological problems. The hospital records of all deliveries during the period January, 2012 till December, 2012 were retrieved and analyzed.

Data from the clinical records were retrieved. Socio demographic information (i.e. age, socio economic condition, years of education, occupation, residing in rural/ urban area) and parity were recorded. Moreover, the outcome variables (i.e. cesarean section or vaginal delivery, elective cesarean section or emergency cesarean section) were also recorded. Elective cesarean section is defined as planned operations at time suiting the women and maternity team; while all other operations were considered as Emergency cesarean section. Importantly, the indicators for cesarean section mentioned in the clinical notes were also recorded. Clinical records with missing or incomplete data were excluded for analysis.

The present study also included the collection primary data on reasons for supporting women choice for caesarian section from obstetricians of Pakistan and Saudi Arabia. The eligibility criteria for inclusion are completion of post graduation training and working in the similar setting for three years or more. Due to limited number of obstetricians working with relevant experience at $\mathrm{MMCH}$, Pakistan and Sabatal Alaya Hospital, Saudi Arabia; the data from obstetricians were collected at the end of Continuing Medical Education (CME) workshop conducted at both study settings. All recruited obstetricians were inquired about reasons for supporting women choice for caesarian section. The question consisted of multiple response items (i.e. women choice or preference, fear of vaginal delivery, previous CS or traumatic delivery, first child disability, respect for women autonomy, and to avoid noncompliance during delivery or legal consequences) where participants can select more than one option.

The study is approved by the institutional ethical review committee of Muhammad Medical College Hospital $(\mathrm{MMCH})$, Pakistan and Sabatal Alaya Hospital, Saudi 
Arabia. Anonymity and confidentiality of the participants data was maintained throughout the research. No unauthorized person has an access to the identifiable patient's as well as the obstetrician's response data. Written informed consent was obtained from all the obstetricians prior to recruitment in the study.

\section{Data analysis}

The data was analysed using SPSS version 21 (IBM, Chicago, IL). The qualitative variables (i.e., age categories, socio economic condition, education, occupation, residence and parity) were compared between women delivered at Muhammad Medical College Hospital (MMCH), Pakistan and Sabatal Alaya Hospital, Saudi Arabia using chi square statistics. The outcome variables proportion of cesarean section, elective cesarean section or emergency cesarean section and indication of cesarean section were also compared for deliveries in the two hospital using chi square statistics. Finally, the individual reasons for supporting women choice for caesarian section were also compared for obstetricians of two regions using chi square statistics. If the assumptions of chi square test were not satisfied Fisher exact test was used. For bivariate analysis p-value $\leq 0.05$ was considered as significant.

\section{Results and Discussion}

The table 1 gives details of the comparison of socio demographics characteristics and parity of women having delivered in Muhammad Medical College Hospital, Pakistan and Sabatal Alaya Hospital, Saudi Arabia. The retrospective analysis included data of eleven hundred and fifty women who delivered in $\mathrm{MMCH}$ and eight hundred and thirty four deliveries in Sabatal Alaya Hospital, Saudi Arabia. There was no significant difference in age and occupation between women who delivered in hospital settings of Pakistan and Saudi Arabia. However, significant difference was found in socio economic condition, education, residence and parity. Greater proportion of women from Pakistan belonged to poor socio economic status compared to Saudi Arabia $(45.1 \%$ vs. $23 \%$; p-value $=0.001)$. Moreover, significantly lesser proportion of Pakistani women had education of eight years or less (48\% vs. $54.2 \%$; p-value $=0.009$ ). Furthermore, significantly a higher percentage of Pakistani women residing in rural areas delivered in Muhammad Medical College Hospital, Pakistan compared to Sabatal Alaya Hospital, Saudi Arabia $(22.9 \%$ Vs. 15.9\%; p-value $=0.001)$. Finally, women delivered at both settings were in majority multiparous, however five or more births were greater among Saudi women (40.1\%) compared to women who delivered in hospital setting of Pakistan (33.9\%). The difference was significant with p-value $<0.01$.

The table 2 gives details of frequency and indication of Caesarian section between the two countries compared. Significantly higher proportion of women from Pakistan, around fifty eight percent were delivered through Caesarian section compared to around thirty four percent in Saudi Arabia. Moreover, significant difference was also found in Elective CS with greater proportion of Saudi women were delivered through Elective CS as compared to Pakistani women. The most common indicators for Elective CS among Pakistani women were previous CS (49.2\%) followed by breech presentation (27.8\%), maternal condition (11.2\%) and maternal request $(7 \%)$. However, the top most indicators for Elective CS among Saudi women were previous CS (48.6\%) followed by breech presentation (22.2\%), maternal request $(14.1 \%)$ and maternal condition $(11.1 \%)$. Significant difference lied between indications of Emergency CS between the two countries with most common reasons as difficult labor (26.5\% vs. $39 \%)$, fetal distress $(20.9 \%$ vs. 17.3\%), Antipartum Hemorrhage $(12.7 \%$ vs. $10.8 \%)$ and breech presentation $(10.2 \%$ vs. $9.7 \%)$.

The table 3 shows comparison of proportion of obstetricians complying with the request for caesarean delivery. Significant difference was found in reasons for support of women choice. Greater proportion of obstetricians from Saudi Arabia compared to those working in Pakistan accounted women choice $(51.8 \%$ Vs $18.2 \%$; p-value < 0.001), previous caesarian section $(87.5 \%$ Vs $68.2 \%$; p-value $=0.035)$, respect for women autonomy (80.4\% Vs 56.8\%; p-value $=0.084)$ and legal consequences if something goes wrong $(58.9 \%$ vs. $15.9 \% ; \mathrm{p}$-value $=0.001$ ) as reasons for supporting caesarean delivery.

The present study reported the higher rate of CS in both countries Saudi Arabia and Pakistan. Though, there were some variations in the indications of Elective and Emergency CS, however the predominant reasons were nearly the same. Importantly, women choice was greatly considered in the developed healthcare setting of Saudi Arabia for Elective CS as compared to Pakistan. Finally, Obstetricians of the two countries have highlighted different reasons for supporting women choice for Elective CS. The present study reported the prevalence of CS as 58\% from the study site in Pakistan. The 
distribution of Elective and Emergency CS were 28\% and $72 \%$ respectively. The top most factors of Elective CS in health settings of Pakistan were previous CS (49\%), breech presentation (27.8\%), maternal condition $(11.2 \%)$ and maternal request as $7 \%$ while difficult labor, fetal stress, APH and breech presentation were identifies as four top most indicators for Emergency CS. An audit to identify CS rate and frequency of different indications conducted at Obstetrics and Gynecology Department of Military Hospital Rawalpindi from September 2011 to February 2012 reported a slightly lower CS rate as $45.5 \%$ and the most common factor was repeat cesarean section $(44.4 \%)$, followed by failed trial of labor $(27.1 \%)$ and fetal distress seen in $165(10.1 \%)$. A retrospective study conducted at Liaquat National Hospital, Karachi reported that Emergency caesarean section was performed on 392(58.5\%) and elective caesarean section was performed on 277(41.4\%) patients (Ehtisham et al., 2014). The predominant causes for caesarean sections were identified as previous caesarean sections (30.9\%) followed by fetal distress (15.2\%) and non-progress of labour (13.9\%). A study comparing the emergency CS rate in year 2005 and 2010 reported a rise of $17.3 \%$ with drastic rise of thirty percent in repeat caesarean sections as indicator of CS (Rafique et al., 2011). A study conducted in rural Sindh, Pakistan from November 2008 to January 2009 reported frequency of CS as $41.4 \%$. A descriptive study conducted in a tertiary care hospital of Hyderabad, Sindh reported rate of cesarean section as $64.7 \%$ with Emergency cesarean section was performed in $225(59.2 \%)$ patients and elective cesarean section in $155(40.7 \%)$. The study also reported Repeat cesarean section followed by dystocia, fetal distress and ante partum hemorrhage as most common indications.

The prevalence of CS in hospital setting of Saudi Arabia was lower as compared to Pakistan and identifies as around $34.1 \%$, with Elective CS comprising of more than one third of all CS. The most common indicators for Elective CS in health settings of Saudi Arabia were previous CS (48.6\%), breech presentation (22.2\%), maternal request $(14.1 \%)$ and maternal condition as $11.1 \%$. while difficult labor, fetal stress, APH and breech presentation remains as four top most indicators for Emergency CS.

Table.1 Comparison of Socio demographic characteristics and parity between women delivered in Pakistan and Saudi Arabia

\begin{tabular}{|c|c|c|c|}
\hline Socio demographic characteristics & $\begin{array}{l}\text { Pakistan } \\
(\mathrm{n}=1150)\end{array}$ & $\begin{array}{l}\text { Saudi Arabia } \\
\quad(n=834)\end{array}$ & P-value \\
\hline \multicolumn{4}{|l|}{ Age categories (Years) } \\
\hline$<20$ years & $48(4.2)$ & $27(3.3)$ & 0.3118 \\
\hline $20-30$ years & $550(47.8)$ & $375(44.9)$ & \\
\hline $31-40$ years & $462(40.2)$ & $366(43.9)$ & \\
\hline$>41$ years & $90(7.8)$ & $66(7.9)$ & \\
\hline \multicolumn{4}{|l|}{ Socioeconomic } \\
\hline Poor & $518(45.1)$ & $192(23)$ & 0.001 \\
\hline Middle & $403(35)$ & $367(44)$ & \\
\hline Upper & $229(19.9)$ & $275(33)$ & \\
\hline \multicolumn{4}{|l|}{ Education } \\
\hline$\leq 8$ years & $552(48)$ & $451(54.2)$ & 0.009 \\
\hline $9-12$ years & $322(28)$ & $225(26.9)$ & \\
\hline$>12$ years & $276(24)$ & $158(18.9)$ & \\
\hline \multicolumn{4}{|l|}{ Occupation } \\
\hline House Wife & $897(78)$ & $659(79.1)$ & 0.624 \\
\hline Working women & $253(22)$ & $175(20.9)$ & \\
\hline \multicolumn{4}{|l|}{ Residence } \\
\hline Urban & $886(77.1)$ & $701(84.1)$ & 0.001 \\
\hline Rural & $264(22.9)$ & $133(15.9)$ & \\
\hline \multicolumn{4}{|l|}{ Parity } \\
\hline Nullparity (0 births) & $150(13.1)$ & $125(14.9)$ & 0.001 \\
\hline Multiparity (1-4 births) & $610(53)$ & $459(55)$ & \\
\hline Grand Multiparity (5+ births) & $390(33.9)$ & $250(40.1)$ & \\
\hline
\end{tabular}

Data presented as frequency (percentage) 
Table.2 Comparison of frequency and indication of Caesarian Section between women delivered

in Pakistan and Saudi Arabia

\begin{tabular}{lccc}
\hline Indication of Caesarian Section & $\begin{array}{c}\text { Pakistan } \\
(\mathbf{n}=\mathbf{1 1 5 0})\end{array}$ & $\begin{array}{c}\text { Saudi Arabia } \\
(\mathbf{n}=\mathbf{8 3 4})\end{array}$ & P-value \\
\hline Caesarian Section & $667(58)$ & $284(34.1)$ & 0.001 \\
Yes & $483(42)$ & $550(65.9)$ & 0.04 \\
No & & & \\
Caesarian Section & $187(28)$ & $99(34.9)$ & 0.352 \\
Elective CS & $480(72)$ & $185(65.1)$ & \\
Emergency CS & & & \\
Elective CS Indicators & $9(4.8)$ & $11(11.1)$ & \\
Fetal condition & $21(11.2)$ & $14(14.1)$ & \\
Maternal condition & $13(7)$ & $22(22.2)$ & \\
Maternal request & $52(27.8)$ & $48(48.6)$ & \\
Breech presentation & $92(49.2)$ & $4(2.2)$ \\
Previous CS & & $5(2.7)$ \\
Emergency CS Indicators & $14(2.9)$ & $6(3.2)$ \\
Fetal condition & $18(3.8)$ & $13(7.0)$ \\
Cord Prolapse & $21(4.4)$ & $15(8.1)$ \\
Twins/ triplets & $47(9.8)$ & $20(10.8)$ \\
Maternal condition & $42(8.8)$ & $18(9.7)$ \\
Previous CS & $61(12.7)$ & $32(17.3)$ \\
Antipartum Hemorrhage (APH) & $49(10.2)$ & $72(39)$ \\
Breech presentation & $101(20.9)$ & \\
Fetal distress & $127(26.5)$ & \\
Difficult Labor & &
\end{tabular}

Data presented as frequency (percentage)

Table.3 Obstetrics reasons for supporting woman's choice for a caesarean delivery independently from other medical or nonmedical indications

\begin{tabular}{lccc}
\hline Reasons for supporting woman's choices & $\begin{array}{c}\text { Pakistan } \\
(\mathbf{n = 4 4 )}\end{array}$ & $\begin{array}{c}\text { Saudi Arabia } \\
(\mathbf{n}=\mathbf{5 6})\end{array}$ & P-value \\
\hline This is her choice & $8(18.2)$ & $29(51.8)$ & 0.001 \\
Fear of Vaginal delivery & $12(27.3)$ & $24(42.9)$ & 0.160 \\
Previous Caesarian section & $30(68.2)$ & $49(87.5)$ & 0.035 \\
Previous traumatic delivery & $31(70.5)$ & $42(75.0)$ & 0.777 \\
Previous intrapartum death & $38(86.4)$ & $44(78.6)$ & 0.458 \\
First child is disabled & $31(70.5)$ & $43(76.8)$ & 0.624 \\
Respect for the women's autonomy & $25(56.8)$ & $45(80.4)$ & 0.019 \\
Avoid possible problems of non-compliance & $10(22.7)$ & $23(41.1)$ & 0.084 \\
Avoid possible legal consequences & $7(15.9)$ & $33(58.9)$ & 0.001 \\
\hline
\end{tabular}

Data presented as frequency (percentage)

The retrospective analysis of deliveries at King Abdulaziz Medical City (KAMC), Riyadh, Saudi Arabia (June 2008 to February 2011) reported the frequency of CS deliveries as slightly less than twenty percent with two thirds $(67 \%)$ of all CS deliveries were emergency CS, and the remaining deliveries were elective CSs (33\%). Difficult labor (35.9\%), fetal distress $(21.9 \%)$ and breech presentation (11.6\%) were the most frequent indications of emergency CS, while previous CS (54.3\%), breech presentation (20.4\%) and maternal request $(10.1 \%)$ ranked first for elective CS (Haider et al., 2009). Other studies have also reported 
that in Saudi Arabia CS rate exceeded the acceptable $15 \%$ rate suggested by the World Health Organization (WHO) (Bondok et al., 2011; Al-Mulhim et al., 2001). Importantly, greater proportion of obstetricians from Saudi Arabia compared to those working in Pakistan accounted women choice (51.8\% Vs 18.2), respect for women autonomy $(80.4 \%$ Vs $56.8 \%)$ and legal consequences if something goes wrong $(58.9 \% \mathrm{Vs}$ $15.9 \%$ ) as reasons for supporting caesarean delivery. Other studies from developed countries have reported similar findings where maternal request for CS are accepted because of respect for maternal autonomy and women choice (Wenstrom et al., 2006).

The study has certain limitations. As the study design was retrospective which has its own limitations i.e. incomplete documentations and missing values. Secondly, maternal and fetal outcomes as a result of vaginal or caesarean deliveries were not reported. Thus, in future prospective studies should be conducted with maternal and fetal outcomes being reported. Moreover, a qualitative study using focus group discussion or open ended questions for Obstetricians would be more revealing to identify reasons for supporting women choice for Elective CS.

\section{Conclusion}

The present study concluded a higher prevalence of Caesarean section both in developed and developing country of Saudi Arabia and Pakistan. The most common indicators for Elective CS in both healthcare settings were previous $\mathrm{CS}$, breech presentation, maternal request and maternal condition. The obstetricians from Saudi Arabia had more fear of legal consequences, and accounted women choice and respect for women autonomy as reasons for supporting women decision of Elective CS.

\section{Recommendations}

It has been recommended that if we want to reduce the rising rate of LSCS. We have to prevent primary caesarean section for that I have following suggestion

1-there should be sufficient skill lab trainings in instrumental deliveries in undergraduates obstetrics and gynecology modules.

2-there must be special attention to be paid towards training in instrumental deliveries of house officer and residents as now a day's doctors are less confident in application of instrumental deliveries, so have low threshold for LSCS.

3-the most important question to be answered in future, should the women right to go for elective caesarean section should be respected every time? Though, it has bad consequences in future, in terms of placenta previa and all its related complications.

\section{References}

Al Rowaily, M.A., Alsalem, F.A., Abolfotouh, M.A. 2014. Cesarean section in a high-parity community in Saudi Arabia: Clinical indications and obstetric outcomes. BMC Pregnancy Childbirth, 14(1).

Al-Mulhim, A., Abu-Heija, A.T., Ali, A.H.M., Bahnasy, A. 2001. Factors affecting the rate and the indications of primary caesarean section. Bahrain Med. Bull., 23(4): 160-162.

Appropriate technology for birth. Lancet, 2(8452): 436437.

Betrán, A.P., Merialdi, M., Lauer, J.A., Bing-Shun, W., Thomas, J., Van Look, P., et al. 2007. Rates of caesarean section: Analysis of global, regional and national estimates. Paediatr. Perinat. Epidemiol., 21(2): 98-113.doi:10.1111/j.13653016.2007.00786.x

Bondok, W.M., El-Shehry, S.H., Fadllallah, S.M. 2011. Trend in cesarean section rate. Saudi Med. J., 32(1): 41-45.

Chigbu, C.O., Ezenyeaku, C.C., Ezenkwele, E.P. 2010. Obstetricians' attitudes to caesarean delivery on maternal request in Nigeria. J. Obstet. Gynaecol., 30(8): 813-817.

Dadipoor, S., Madani, A., Alavi, A., Roozbeh, N., Safari, Moradabadi, A. 2016. A survey of the growing trend of caesarian section in Iran and the world: A review article. Iran J. Obstet. Gynecol. Infertil., 19(27): 8-17. doi:10.22038/ijogi.2016.7847

Ehtisham, S., Akhtar Hashmi, H. 2014. Determinants of caesarean section in a tertiary hospital. J. Pak. Med. Assoc., 64(10): 1175-1178.

Gunnervik, C., Sydsjö, G., Sydsjö, A., Selling, K.E., Josefsson, A. 2008. Attitudes towards cesarean section in a nationwide sample of obstetricians and gynecologists. Acta Obstet. Gynecol. Scand, 87(4): 438-444. doi:10.1080/00016340802001711

Habiba, M., Kaminski, M., Da Frè, M., Marsal, K., Bleker, O., Librero, J., et al. 2006. Caesarean section on request: A comparison of obstetricians' attitudes in eight European countries. BJOG Int. J. Obstet. Gynaecol., 113(6): 647-656. 
Haider, G., Zehra, N., Munir, A.A., Haider, A. 2009. Frequency and indications of cesarean section in a tertiary care hospital. Pak. J. Med. Sci., 25(5): 791796.

Hall, M.H., Bewley, S. 1999. Maternal mortality and mode of delivery. Lancet, 354(9180): 776.

Nizam, K., Haider, G., Memon, N., Haider, A. 2010. Cesarean section rate: Much room for reduction. Rawal Med. J., 35(1): 19-22.

Penn, Z., Ghaem-Maghami, S. 2001. Indications for caesarean section. Best Pract. Res. Clin. Obstet. Gynaecol., $15(1)$ :

$1-15$. doi:10.1053/beog.2000.0146

Pevzner, L., Preslicka, C., Bush, M.C., Chan, K. Women's attitudes regarding mode of delivery and cesarean delivery on maternal request. J. Matern Fetal Neonatal Med., 24(7): 894-899.

Rafique, S., Raana, G.E. 2005. High emergency caesarean section rate - A comparison of indications in years 2005 and 2010. Pak. J. Med. Health Sci., 5(3): 489-491.

Sajjad, R., Amjad, C.A., Zia-Ul-Haq, M., Iqbal, A. 2014. An audit of cesarean sections in Military Hospital Rawalpindi. Anaesth. Pain Intensive Care, 18(2): 172-175.

Wenstrom, K.D. 2006. Caesarean section on request: A comparison of obstetricians' attitudes in eight European countries - Commentary. Obstet. Gynecol. Surv., 61(9): 575-576.

\section{How to cite this article:}

Farzana Rizwan Arain. 2017. Rising Rate of Caesarean Section - A Global Problem. Int.J.Curr.Res.Aca.Rev. 5(2), 44-50. doi: http://dx.doi.org/10.20546/ijcrar.2017.502.006 